\title{
Proposta de Emenda à Constituição (PEC) 215
}

Liana Amin Lima da Silva ${ }^{1}$

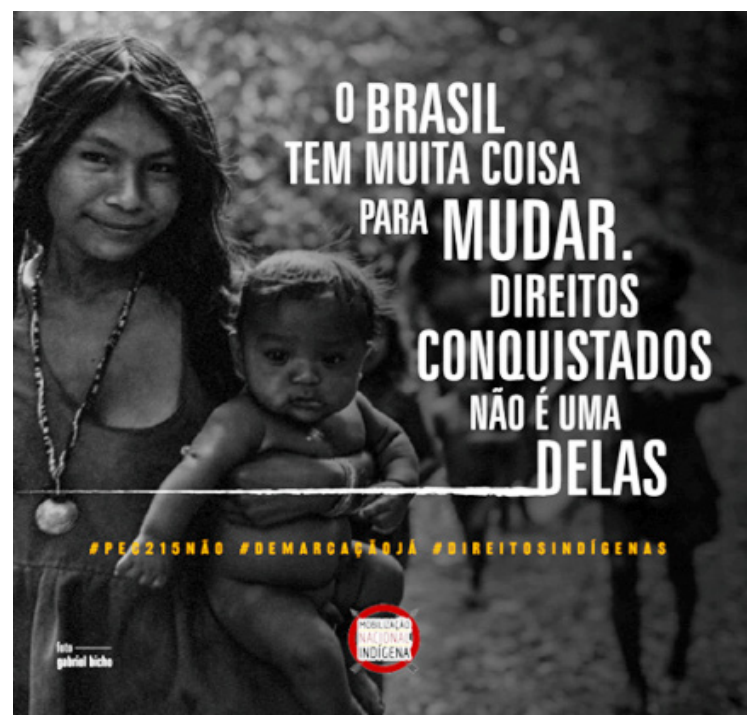

Fig.1. "O Brasil tem muita coisa para mudar. Direitos conquistados não é uma delas." Mobilização Nacional Indígena (Foto: Gabriel Bicho).

As Emendas à Constituição estão previstas no artigo 60 da Constituição Federal, que em seus parágrafos condicionam e subordinam o

1 Doutoranda em Direito Socioambiental e Sustentabilidade pela Pontifícia Universidade Católica do Paraná (PUCPR), bolsista PDSE/CAPES, com estágio de doutorado na Universidad Nacional da Colombia (UNAL). Professora colaboradora da Licenciatura Indígena em Políticas Educacionais e Desenvolvimento Sustentável da Universidade Federal do Amazonas (UFAM). Advogada e educadora popular. Associada ao IPDMS. E-mail: lianalima@gmail.com 
poder reformador que é exercido pelo Congresso Nacional, nos limites da competência para alterar a Constituição. Visando ao respeito e àsupremacia da ordem constitucional estabelecida pelo Poder Constituinte originário, o processo legislativo para tramitação de propostas de emendas constitucionais é especial e mais restritivo que o processo legislativo ordinário.

O artigo $60, \S 2^{\circ}$ dispõe que a proposta de emenda à Constituição será discutida e votada em cada casa do Congresso Nacional (Câmara dos Deputados e Senado Federal), em dois turnos, considerando-se aprovada se obtiver, em ambos, três quintos dos votos dos respectivos membros.

A eficácia das regras jurídicas produzidas pelo poder constituinte (redundantemente chamado de 'originário') não está sujeita a nenhuma limitação normativa, seja de ordem material, seja formal, porque provém do exercício de um poder de fato ou suprapositivo. Já as normas produzidas pelo poder reformador, essas têm sua validez e eficácia condicionadas à legitimação que recebam da ordem constitucional. Daí a necessária obediência das emendas constitucionais às chamadas cláusulas pétreas. ${ }^{2}$

As cláusulas pétreas são limitações ao poder reformador expressas na Constituição e estão previstas no artigo $60, \S 4^{\circ}$. Entre as cláusulas pétreas, cumpre-nos destacar, para fins da reflexão crítica sobre a Proposta de Emenda à Constituição (PEC) n. 215/2000, que não será objeto de deliberação a proposta tendente a abolir: a separação dos Poderes (inciso III); os direitos e garantias fundamentais (inciso IV).

A PEC 215/ 2000 é de autoria do Deputado Amir Morais Sá (PL/RR) e tem como objetivo a transferência das responsabilidades do Poder Executivo na demarcação e titulação de terras indígenas e quilombolas para o Poder Legislativo. Os procedimentos administrativos de

2 Cf. BRASIL. SUPREMO TRIBUNAL FEDERAL (STF). A Constituição e o Supremo. Artigo 60. Ação Direta de Inconstitucionalidade ADI 2.356-MC e ADI 2.362-MC, rel. min. Ayres Britto, julgamento em 25-11-2010, Plenário, DJE de 19-5-2011. Disponível em: <http://www.stf.jus.br/portal/constituicao/artigobd.asp?item=\%20783>. Acesso em: $10 \mathrm{de}$ janeiro de 2016. 
demarcação e titulação são competência da Fundação Nacional do Índio (FUNAI) e do Instituto Nacional de Colonização e Reforma Agrária (INCRA) para terras indígenas e quilombolas, respectivamente. Com a proposta de emenda constitucional, o Legislativo busca ter a última palavra em matéria de homologação da demarcação de terras, ou seja, a competência exclusiva para aprovar a demarcação das terras indígenas e retificar as demarcações já homologadas pelo Poder Executivo.

O direito originário dos povos indígenas sobre as terras que tradicionalmente ocupam está consagrado no artigo 231 da Constituição Federal brasileira. O artigo 68 do Ato das Disposições Constitucionais Transitórias (ADCT) reconhece expressamente os direitos das comunidades remanescentes dos quilombos à propriedade permanente das terras que ocupam.

Nos espaços políticos, as forças conservadoras oligárquicas têm alcançado mudanças legislativas que representam retrocessos em matéria de direitos humanos de mulheres, LGBTI, ambiental e de grupos étnicos. Na legislatura atual (2015/2018), do total de 513 Deputados, 257 (51\%) representam a Frente Parlamentar da Agropecuária, chamada também de "Bancada Ruralista", que defende o cultivo de sementes transgênicas, monocultivos e a utilização de áreas protegidas (terras indígenas, territórios tradicionais e unidades de conservação) para mega-projetos extrativos, como hidrelétricas e mineração. Ainda que haja no Congresso Nacional a Frente Parlamentar em Apoio aos Povos Indígenas ${ }^{3}$, composta por parlamentares não indígenas que defendem a demanda e reivindicação dos direitos indígenas e de outras minorias étnicas, importante notar que não há no Brasil uma circunscrição nacional especial para legitimar a participação dos próprios representantes dos povos indígenas, de comunidades quilombolas e tradicionais que confira a essas minorias étnicas representatividade política no âmbito do Congresso Nacional.

3 Cf. BRASIL. CÂMARA DOS DEPUTADOS. Frente Parlamentar em Apoio aos Povos Indígenas. Disponível em: <http://www.camara.leg.br/internet/deputado/frenteDetalhe. asp?id=53493>. Acesso em 20 de janeiro de 2016. 
No caso de aprovação da PEC 215, na prática significa que a definição sobre as terras onde os indígenas poderão exercer seu direito à permanência física e cultural está sujeita às maiorias políticas de ocasião, conforme apontou a própria FUNAI em nota sobre a PEC 215/00, publicada em 28 de outubro de $2015 .{ }^{4}$

A PEC 215 afronta a Constituição Federal ao prever também a possibilidade de arrendamento das terras indígenas, que são bens da União, definidos como inalienáveis e indisponíveis, conforme o artigo 231, § $4^{\circ}$. $^{\circ}$

Outro ponto polêmico da PEC 215 é tentar incorporar na Constituição Federal as condicionantes que estabelecem exceções ao usufruto exclusivo dos povos indígenas em relação às terras indígenas que ocupam (posse permanente), assim como incorporar o denominado marco temporal, restrições criadas pelo Supremo Tribunal Federal (STF) no âmbito do julgamento do caso da demarcação da Terra Indígena Raposa Serra do Sol (Roraima).

Referida decisão estabeleceu o critério do marco temporal de ocupação para a verificação da posse da terra, com base na data de promulgação da Constituição Federal (05 de outubro de 1988), para fins de demarcação e titulação das terras indígenas. Com a criação e aplicação desse critério, a Segunda Turma do STF ignora que a proteção constitucional aos direitos originários territoriais dos povos indígenas existe desde a Constituição de 1934, assim como ignora o genocídio e as violações de direitos humanos dos povos indígenas e a usurpação de terras indígenas no período da ditadura militar, já oficialmente reconhecidos no relatório final da Comissão Nacional da Verdade (CNV). ${ }^{6}$

4 Cf. BRASIL. FUNAI [FundaçãoNacional do Índio].Nota da Funaisobre a PEC 215/00. Disponível em: <http://www.funai.gov.br/index.php/comunicacao/noticias/3494-nota-dafunai-sobre-a-pec-215-00>. Publicado em 28 de outubro de 2015. Acesso em 11 de janeiro de 2016.

5 Para leitura do artigo 231 e do texto substitutivo da PEC 215, verquadroanexo.

6 Cf. BRASIL. Comissão Nacional da Verdade. Relatório: Textos temáticos. Brasília: CNV, 2014. Disponível em: http://www.cnv.gov.br/images/pdf/relatorio/volume_2_digital.pdf . Acesso em 28 de janeiro de 2016. 
Nos Embargos de Declaração (recurso cabível quando na sentença ou acórdão há obscuridade, contradição, omissão ou dúvida) que foram interpostos pela Procuradora-Geral da República, Dra. Deborah Macedo Duprat, destacou-se a crítica de que "não cabe ao STF traçar parámetros abstratos de conduta, máxime em contexto em que os mesmos não foram sequer objeto de discussão no curso da lide" (fl.10.158). Nesse sentido, o STF aclarou que "a decisão proferida na Petição 3.388 não vincula juízes e tribunais quando do exame de outros processos, relativos a terras indígenas diversas". ${ }^{7}$

As 19 condicionantes e o critério do marco temporal vão na contramão dos direitos garantidos pela Convenção n. 169 da Organização Internacional do Trabalho (OIT) sobre Povos Indígenas e Tribais e na Declaração das Nações Unidas sobre os Direitos dos Povos Indígenas,especialmente em relação aos direitos territoriais, ao direito à autodeterminação e ao direito à consulta prévia, livre e informada.

Com as Mobilizações Nacionais Indígena e Quilombola, coordenadas pela Articulação dos Povos Indígenas do Brasil (APIB) e pela Coordenação Nacional de Articulação das Comunidades Negras Quilombolas (CONAQ), os povos indígenas e quilombolas vêm ao longo dos últimos anos repudiando a PEC 215.

Em 2004, a PEC 215 havia sido arquivada por ser considerada inconstitucional com parecer do deputado Luiz Couto (PT-PE) na Comissão de Constituição Justiça e Cidadania (CCJC) da Câmara dos Deputados. Em 21 de março de 2012, desarquivada, a PEC 215 foi novamente avaliada pela CCJC, com parecer favorável pelo Deputado Osmar Serraglio (PMDB-PR).

Nessa ocasião, a CCJC aprovou a admissibilidade constitucional da proposição principal, com oferecimento de emenda saneadora de inconstitucionalidade, que exclui do texto original a possibilidade de o

7 BRASIL. Supremo Tribunal Federal (STF).Acórdão. Embargos de DeclaraçãonaPetição 3.388 Roraima; JulgamentoPlenário, Data: 23/10/2013. Citações: parágrafos 49, 55, 58 (pág. 21, 23, 25). Disponível em: <http://www.conjur.com.br/dl/decisao-barroso-raposaserra-sol.pdf>. Acessoem 28 de janeiro de 2016. 
Congresso Nacional rever as demarcações já concluídas, por entendê-la atentatória ao preceito do art. $60, \S 4^{\circ}$, IV, da Constituição Federal.

Em 17 de novembro de 2014, o mesmo Deputado, agora relator da Comissão Especial da PEC 215, apresentou um Substitutivo, incorporando a admissão do arrendamento de terras indígenas, fazendo referência às condicionantes do STF no caso Raposa Serra do Sol, entre outros pontos que não eram matéria da proposta inicialmente apresentada. Em 27 de outubro de 2015, a PEC 215 foi aprovada pela Comissão Especial da Câmara dos Deputados. Seguirá para votação no Plenário da Câmara em dois turnos, devendo haver intervalo de cinco sessões entre uma e outra votação. Para ser aprovada, precisa de pelo menos 308 votos (3/5 dos deputados) em cada uma das votações.

Caso aprovada na Câmara, a PEC seguirá para o Senado, onde é analisada pela Comissão de Constituição, Justiça e Cidadania (CCJ) e depois pelo Plenário, no qual precisa ser votada novamente em dois turnos. Se o Senado aprovar o texto como o recebeu da Câmara, a emenda é promulgada pelas Mesas da Câmara e do Senado. Se o texto for alterado, volta para a Câmara, para ser votado novamente. A proposta vai de uma Casa para outra (o chamado pingue-pongue) até que o mesmo texto seja aprovado pelas duas Casas. ${ }^{8}$

O processo legislativo da PEC 215 deve ser considerado eivado porque desrespeita o direito à participação e à consulta prévia no que toca os atos legislativos que afetem os povos indígenas e comunidades tradicionais, de acordo com a Convenção n. 169 da OIT sobre Povos Indígenas e Tribais, ratificada pelo Brasil em 2002 e promulgada pelo Decreto n. 5.051 de 2004. A consulta prévia é um mecanismo de participação e de exercício da livre determinação que deve ser respeitado inclusive no trâmite legislativo referente à reforma de normas constitucionais que afetam diretamente os povos interessados.

8 Cf. CÂMARA DOS DEPUTADOS. Conheça a tramitação de PECs. Disponível em: http:// www2.camara.leg.br/camaranoticias/noticias/70153.html. CONGRESSO NACIONAL. RegimentoComumdoCongressoNacional. Resolução n. 1, de 1970-CN.Disponívelem: http://www2.senado.leg.br/bdsf/bitstream/handle/id/70321/RegCN.pdf?sequence=7 . 
A Secretaria de Governo da Presidência da República e o Ministério da Justiça manifestaram a posição de que a PEC 215 ofende o principio da separação dos poderes. No discurso de abertura da $1^{\mathrm{a}}$. Conferência Nacional de Política Indigenista, ocorrida em Brasília, 15 a 17 de dezembro de 2015, a Presidenta da República Dilma Rousseff reiterou a declaração da posição do Governo contrária à PEC 215 por retirar poderes do Executivo, manifestando que a demarcação de terras deve persistir como prerrogativa do Poder Executivo, no sentido do respeito à autonomia dos Poderes. ${ }^{9}$ Assim como na nota publicada pela FUNAI (2015), foi manifestada a irrestrita oposição à PEC 215, reforçando a inconstitucionalidade em vários aspectos.

No texto da proposta, é nítida a categorização dos indígenas em diferentes estágios de desenvolvimento e inserção na sociedade nacional, o que denota a lógica integracionista, de tutela e de assimilação cultural que foi justamente superada pelo advento da promulgação da Constituição em 1988, com o reconhecimento da diversidade cultural e dos direitos dos povos indígenas, sua organização social própria (leia-se jurisdições próprias), costumes, línguas, crenças e tradições (artigo 231).

Em suma, a PEC 215 ameaça os direitos garantidos na Constituição (artigo 231 e 232), representando um retrocesso nas normas constitucionais que tratam de direitos fundamentais, o que é inadmissível por se tratar de cláusulas pétreas, além de violar os direitos previstos na Convenção 169 da OIT e na Declaração das Nações Unidas sobre os Direitos dos Povos Indígenas.

Os direitos originários dos povos e comunidades tradicionais estão relacionados com os seus direitos à vida, à existência e à integridade física, cultural e espiritual. $O$ direito ao território é congênito à aparição ou o nascimento das próprias comunidades.

9 Cf. BRASIL. PALÁCIO DO PLANALTO, Presidência da República. Discurso da Presidenta da República, Dilma Rousseff, durante a $1^{\text {a }}$ Conferência de Política Indigenista - Brasília/DF. Disponível em: <http://www2.planalto.gov.br/acompanhe-o-planalto/discursos/discursos-dapresidenta/discurso-da-presidenta-da-republica-dilma-rousseff-durante-a-1a-conferenciade-politica-indigenista-brasilia-df>; <http://blog.planalto.gov.br/assunto/pec-215/ > Acesso em 05 de janeiro de 2016. 
Negar o direito originário à terra é negar o direito à existência dos povos indígenas e quilombolas, os mantendo na invisibilidade, enquanto a Constituição de 1988 tratou de levá-los à visibilidade política e jurídica.

\section{ANEXO}

Tabela 1. Quadro comparativo da redação do texto do artigo 231 da Constituição Federal com o texto substitutivo da Proposta de Emenda à Constituição PEC 215-A, de 2000.

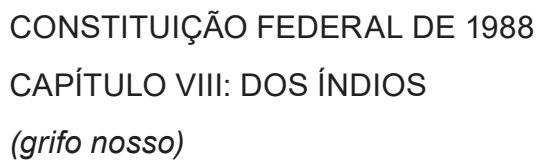

\section{$\S 1^{\circ}$ São terras tradicionalmente} ocupadas pelos índios as por eles habitadas em caráter permanente, as utilizadas para suas atividades produtivas, as imprescindíveis à preservação dos recursos ambientais necessários a seu bem-estar e as necessárias a sua reprodução física e cultural, segundo seus usos, costumes e tradições.

$\S 2^{\circ}$ As terras tradicionalmente ocupadas pelos índios destinam-se a sua posse permanente, cabendo-lhes o usufruto exclusivo das riquezas do solo, dos rios e dos lagos nelas existentes.

$\S 3^{\circ} \mathrm{O}$ aproveitamento dos recursos hídricos, incluídos os potenciais energéticos, a pesquisa e a lavra das riquezas minerais em terras indígenas só podem
SUBSTITUTIVO A PROPOSTA DE EMENDA À CONSTITUIÇÃO PEC 215A, DE 2000 (grifo nosso) $\mathrm{O}$ art. 231 da Constituição Federal passa a vigorar com as seguintes alterações:

"Art. 231

$\S 1^{\circ}$ São terras tradicionalmente ocupadas pelos índios as que, em 5 de outubro de 1988, atendiam simultaneamente aos seguintes requisitos:

I - por eles habitadas, em caráter permanente;

II - utilizadas para suas atividades produtivas,

III - imprescindíveis à preservação dos recursos ambientais necessários ao seu bem-estar e à sua reprodução física e cultural, segundo seus usos, costumes e tradições."(NR)

$\S 2^{\circ}$ As terras tradicionalmente ocupadas pelos índios, destinam-se a sua posse permanente, cabendo-lhes o usufruto das riquezas do solo, dos rios e dos lagos nelas existentes, podendo explorá-las, direta ou indiretamente, na forma da lei, excetuando-se as seguintes situações: 
ser efetivados com autorização do Congresso Nacional, ouvidas as comunidades afetadas, ficando-lhes assegurada participação nos resultados da lavra, na forma da lei.

\section{$\S 4^{\circ}$ As terras de que trata este} artigo são inalienáveis e indisponíveis, e os direitos sobre elas, imprescritíveis.

$\S 5^{\circ}$ É vedada a remoção dos grupos indígenas de suas terras, salvo, «ad referendum» do Congresso Nacional, em caso de catástrofe ou epidemia que ponha em risco sua população, ou no interesse da soberania do País, após deliberação do Congresso Nacional, garantido, em qualquer hipótese, o retorno imediato logo que cesse o risco.

$\S 6^{\circ}$ São nulos e extintos, não produzindo efeitos jurídicos, os atos que tenham por objeto a ocupação, o domínio e a posse das terras a que se refere este artigo, ou a exploração das riquezas naturais do solo, dos rios e dos lagos nelas existentes, ressalvado relevante interesse público da União, segundo o que dispuser lei complementar, não gerando a nulidade e a extinção direito a indenização ou a ações contra a União, salvo, na forma da lei, quanto às benfeitorias derivadas da ocupação de boa fé.

$\S 7^{\circ}$ Não se aplica às terras indígenas o disposto no art. $174, \S 3^{\circ}$ e $\S 4^{\circ}$.

Art. 232. Os índios, suas comunidades e organizações são partes legítimas para ingressar em juízo em defesa de seus direitos e interesses, intervindo o Ministério Público em todos os atos do processo.
I - ocupações configuradas como de relevante interesse público da União, nos termos estabelecidos por lei complementar;

II - instalação e intervenção de forças militares e policiais, independentemente de consulta às comunidades indígenas;

III - instalação de redes de comunicação, rodovias, ferrovias e hidrovias e edificações destinadas à prestação de serviços públicos, especialmente os de saúde e de educação, vedada a cobrança de tarifas de qualquer natureza;

IV - área afetada por unidades de conservação da natureza;

$\mathrm{V}$ - os perímetros urbanos.

$\mathrm{VI}$ - ingresso, trânsito e permanência autorizada de não índios, inclusive pesquisadores e religiosos, vedada a cobrança de tarifas de qualquer natureza. (NR)

$\S 8^{\circ}$ É vedada a ampliação de terra indígena já demarcada. (NR)

$\S 9^{\circ} \mathrm{A}$ delimitação definitiva das terras indígenas far-se-á por lei, competindo ao Poder Executivo propor em projeto de lei de sua iniciativa privativa os limites e confrontações da área indígena, ou, havendo conflito fundiário, a permuta de áreas, assegurada a participação dos entes federados no procedimento administrativo relativo às encravadas em seus territórios. (NR)

$\S 10$. As comunidades indígenas em estágio avançado de interação com os não-índios podem se autodeclarar, 


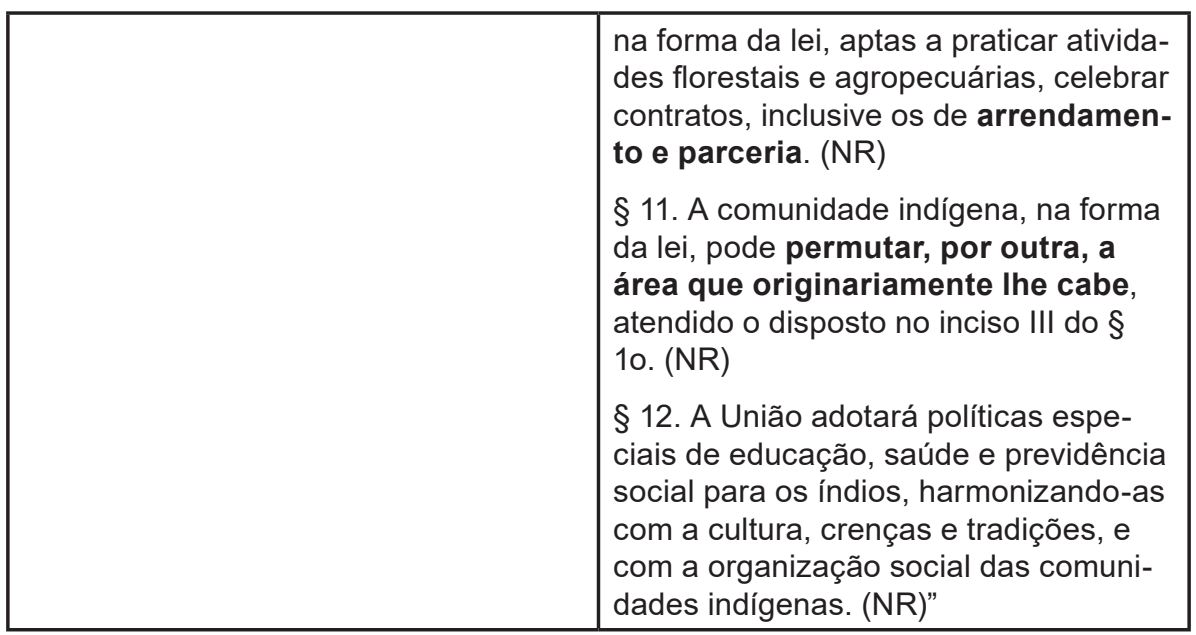

Tabela 2. Proposições que foram apensadas à PEC 215/ 2000.

À PEC 215/2000 foram apensadas às seguintes proposições:

PEC 579/2002: Dá nova redação ao $\S 1^{\circ}$ do art. 231 da Constituição Federal, determinando que a demarcação das terras indígenas deva ser submetida à aprovação do Congresso Nacional.

PEC 257/2004: Tem como propósito dar nova redação ao $\S 1^{\circ}$ do art. 231 da Constituição, acrescentando ao texto original disposição que submete a demarcação das terras indígenas à "audiência das Assembleias Legislativas dos Estados".

PEC 275/2004: Altera a redação dos artigos 49, inciso XVI, e 231, caput, para outorgar ao Congresso Nacional a competência para autorizar a demarcação das terras indígenas, a exploração e o aproveitamento de recursos hídricos e minerais e a pesquisa e lavra das riquezas minerais no interior dessas áreas. À União compete demarcar as terras indígenas, ad referendum do Congresso Nacional.

PEC 319/2004: Tem redação e objetivos similares à PEC 275/2004, alterando a redação dos artigos 49, inciso XVI, e 231, caput, da Constituição.

PEC 156/2003: Acrescenta parágrafo ao art. 231 da Constituição Federal e dá nova redação ao $\S 7^{\circ}$ renumerado, propondo a preservação das áreas ocupadas por pequenas propriedades rurais exploradas em regime de economia familiar, excluindo-as da demarcação das terras indígenas. Estende o direito de indenização aos títulos havidos e benfeitorias erigidas comprovadamente em boa fé.

PEC 37/2007: Dá nova redação ao art. 231 da Constituição, prevendo a criação de reservas indígenas por meio de lei, cujo projeto de iniciativa do Poder Executivo será instruído com estudo antropológico e levantamento fundiário.

PEC 117/2007: Dá nova redação ao art. 231 da Constituição, outorgando à União a competência para demarcar as terras indígenas por lei. 
PEC 411/2009: Acrescenta $\S 8^{\circ}$ ao art. 231 da Constituição, estabelecendo que as terras indígenas serão demarcadas por lei de iniciativa do Poder Executivo.

PEC 415/2009: Dá nova redação ao § $4^{\circ}$ do art. 231 da Constituição, dispondo sobre a permuta, ad referendum do Congresso Nacional, de áreas indígenas por outras de igual extensão.

PEC 161/2007: Altera o inciso III do art. 225, o § $4^{\circ}$ do art. 231, da Constituição Federal, e o art. 68 do Ato das Disposições Constitucionais Transitórias, estabelecendo que a criação, alteração e a supressão de espaços territoriais a serem especialmente protegidos, a demarcação de terras indígenas e a emissão do título de propriedade em favor dos remanescentes das comunidades de quilombos far-se-ão por meio de lei.

PEC 291/2008: Altera o inciso III do $\S 1^{\circ}$ do art. 225 da Constituição, prevendo que a criação, a alteração e a supressão de espaços territoriais a serem especialmente protegidos far-se-ão por lei.

\section{REFERÊNCIAS}

BRASIL. Constituição da República Federativa do Brasil, de 5 de outubro de 1988. Disponível em: <http://www.planalto.gov.br/ccivil_03/ Constituicao/ Constituicao.htm>. Acesso em 11 de janeiro de 2016.

. Decreto n. 5.051, de 19 de abril de 2004. Promulga a Convenção no 169 da Organização Internacional do Trabalho - OIT sobre Povos Indígenas e Tribais. Disponível em: <http://www.planalto.gov.br/ ccivil_03/_ato2004-2006/2004/decreto/d5051.htm>. Acesso em 11 de janeiro de 2016.

. Comissão Nacional da Verdade. Relatório: Textos temáticos. Brasília: CNV, 2014. Disponível em: http://www.cnv.gov.br/images/pdf/ relatorio/ volume_2_digital.pdf . Acesso em 28 de janeiro de 2016.

. CÂMARA DOS DEPUTADOS. Parecer. Comissão Especial destinada a proferir parecer à Proposta de Emenda à Constituição $n^{\circ}$ 215-A, de 2000, que "acrescenta o inciso XVIII ao artigo 49; modifica o $\S 4^{\circ}$ e acrescenta o $\S 8^{\circ}$, ambos no art. 231, da Constituição Federal", e apensadas. (DEMARCAÇÃO DE TERRAS INDÍGENAS). Relator Dep. Osmar Serraglio. Em 17 de novembro de 2014. Disponível em: <http:/l www2.camara.leg.br/proposicoesWeb/prop_mostrarintegra; jsessioni 
$d=42974111701 B 8 B 7 E 9 D 9 F F 73518588 B C 1$. proposicoesWeb2?codte or $=1288819 \&$ filename$=$ Tramitacao-PEC+215/2000>. Acesso em $11 \mathrm{de}$ janeiro de 2016.

. CONGRESSO NACIONAL. Regimento Comum do Congresso Nacional. Resolução n. 1, de 1970-CN, com alterações posteriores, até 2006 e legislação conexa. Brasília: CN, 2007. Disponível em: http://www2.senado.leg.br/bdsf/bits tream/handle/id/70321/RegCN. pdf? sequence $=7$

. FUNAI [FundaçãoNacional do Índio].Nota da Funai sobre a PEC 215/00. Disponível em: <http://www.funai.gov.br/index.php/comunicacao/noticias/3494-nota-da-funai-sobre-a-pec-215-00>. Publicado em 28 de outubro de 2015. Acesso em 11 de janeiro de 2016.

. MPF [Ministério Público Federal]. Nota Técnica: A PEC 215/00 e as Cláusulas Pétreas. Por: Daniel Sarmento, Procurador Regional da República. Rio de Janeiro, 03 de setembro de 2013. Disponível em: <https://mobilizacaonacionalindigena.files.wordpress.com/2014/12/ pec-215_nota-tc3a9cnica-mpf.pdf>. Acesso em 11 de janeiro de 2016.

. PALÁCIO DO PLANALTO, Presidência da República. Discurso da Presidenta da República, Dilma Rousseff, durante a $1^{a}$ Conferência de Política Indigenista - Brasília/DF. Disponível em: <http:// www2.planalto.gov.br/acompanhe-o-planalto/discursos/discursos-da-presidenta/discurso-da-presidenta-da-republica-dilma-rousseff-durante-a-1a-conferencia-de-politica-indigenista-brasilia-df>; <http://blog.planalto.gov.br/assunto/pec-215/ > Acesso em 05 de janeiro de 2016.

. SUPREMO TRIBUNAL FEDERAL (STF). A Constituição e o Supremo. Artigo 60. Ação Direta de Inconstitucionalidade ADI 2.356MC e ADI 2.362-MC, rel. min. Ayres Britto, julgamento em 25-11-2010, Plenário, DJE de 19-5-2011. Disponível em: <http://www.stf.jus.br/ portal/constituicao/artigobd. asp?item $=\% 20783$. Acesso em: $10 \mathrm{de}$ janeiro de 2016. 
Supremo Tribunal Federal (STF). Acórdão. Embargos de Declaração na Petição 3.388 Roraima; Julgamento Plenário, Data: 23/10/2013. Citações: parágrafos 49, 55, 58 (pág. 21, 23, 25). Dsiponível em: <http://www.conjur.com.br/dl/decisao-barroso-raposa-serra-sol.pdf>. Acesso em 28 de janeiro de 2016.

ISA [Instituto Socioambiental]. Análise do Substitutivo à Proposta de Emenda Constitucional $n^{\circ} 215-A$ e propostas apensas. Por: Maurício Guetta, advogado. Programa de Política e Direito Socioambiental Instituto Socioambiental (ISA). Brasília, 01 de dezembro de 2014. Disponível: <https://mobilizacaonacionalindigena.files.wordpress.com/2014/12/ parecer-substitutivo-c3a0-pec-215-a-e-propostas-apensas.pdf>. Acesso em 11 de janeiro de 2016. 